\title{
The Epistemic Status of the Imagination ${ }^{1}$
}

\author{
Joshua Myers \\ New York University \\ Forthcoming in Philosophical Studies. Please cite published version.
}

\begin{abstract}
Imagination plays a rich epistemic role in our cognitive lives. For example, if I want to learn whether my luggage will fit into the overhead compartment on a plane, I might imagine trying to fit it into the overhead compartment and form a belief which is justified on the basis of this imagining. But what explains the fact that imagination has the power to justify beliefs, and what is the structure of imaginative justification? In this paper, I answer these questions by arguing that imaginings manifest an epistemic status: they are epistemically evaluable as justified or unjustified. This epistemic status grounds their ability to justify beliefs, and they accrue this status in virtue of being based on evidence. Thus, imaginings are best understood as justified justifiers. I argue for this view by way of showing how it offers a satisfying explanation of certain key features of imaginative justification that would otherwise be puzzling. I also argue that imaginings exhibit a number of markers of the basing relation, which further motivates the view that imaginings can be based on evidence. The arguments in this paper have theoretically fruitful implications not only for the epistemology of imagination, but for accounts of reasoning and epistemic normativity more generally.
\end{abstract}

\section{Introduction}

The imagination plays a rich epistemic role in our cognitive lives. If I want to learn whether I am able to jump across a small stream, I might imagine myself attempting to jump across and see if I clear it. If I want to learn whether two ingredients will go together in a dish I am cooking, I might imagine those two flavors together to see whether it results in a pleasant experience. If I want to learn why a friend of mine is angry with me, I might imagine myself in their shoes to see if anything I did could be perceived as a slight. Examples like these motivate the view that imagination can justify beliefs. Although this thesis has become increasingly popular in recent years, there has been surprisingly little

\footnotetext{
${ }^{1}$ Special thanks to Paul Boghossian for insightful discussion and valuable feedback at every stage of this project. Thanks also to David Chalmers, Jane Friedman, Andrew Lee, Jim Pryor, an anonymous reviewer, and participants at the Fiction, Imagination, and Epistemology conference at Ruhr-Universität Bochum for helpful comments.
} 
discussion in the philosophical literature regarding the nature and structure of imaginative justification.

In this paper, I will argue that imaginings are justified justifiers. In other words, I will argue that imaginings are capable of manifesting an epistemic status and that their ability to justify beliefs depends on this epistemic status. To have an epistemic status is to be evaluable as either epistemically justified or epistemically unjustified. Thus, according to the view that I will be defending, imaginings fall within the scope of epistemic normativity. Not only can one believe in an epistemically better or worse manner, but one can also imagine in an epistemically better or worse manner.

The thesis that imaginings can have an epistemic status is novel and surprising. It conflicts with many widely held views about the nature of the imagination, the structure of imaginative justification, and the scope of epistemic normativity. In order to further motivate and elaborate this view, I will argue for the supplementary thesis that imaginings can be epistemically based on evidence. This thesis is philosophically significant in its own right. It also functions as an independent argument for the thesis that imaginings can have epistemic status. Furthermore, it goes some way towards explaining why that thesis is true. Imaginings are epistemically justified or unjustified at least partially in virtue of being based on good or bad evidence.

I begin in $\S 2$ by laying the groundwork for the paper by making some preliminary remarks about the imagination. In $\S 3$ I motivate the thesis that imaginings can justify beliefs and defend it against two objections. Next, in $\S 4$ I argue that in order for imaginings to have justificatory force they must be constrained by states which themselves have justificatory force. Most centrally, in $\S 5$ I argue that imaginings can have epistemic status on the basis that this 
offers the best explanation of the epistemic relation between imaginings and their constrainers. Finally, in $\S 6$ I argue that imaginings can be epistemically based on evidence. Taken together, these arguments support the view that imaginings have justificatory force in virtue of themselves being epistemically justified and that imaginings are epistemically justified in virtue of being properly based on good evidence. In other words, imaginings are justified justifiers.

\section{Kinds of Imagination}

First, it will be useful to think about the different ways that the imagination is used and the different ways it can be constrained. It is commonly held that there are two kinds of imagination: sensory imagination and propositional imagination. ${ }^{2}$ Sensory imagination involves mental imagery and is typically associated with phenomenal experience. It is plausibly a kind of offline perceptual representation in the absence of any sensory stimulation. Paradigmatic examples of sensory imagination include imagining the color red or imagining what your favorite song sounds like. On the other hand, propositional imagination need not involve any mental imagery. Paradigmatic examples of propositional imagination include imagining that the next president will be a woman, or that the twig in my hand is a sword, without any accompanying imagery or sensory phenomenal experience. It involves merely imaginatively representing that something is the case, similar to merely entertaining or assuming a proposition. In what follows, I set propositional imagination to the side and restrict my attention to sensory imagination. Unless otherwise specified, all uses of "imagination" should be taken to refer to sensory imagination.

\footnotetext{
${ }^{2}$ Sensory imagination is sometimes also referred to as perceptual or imagistic imagination. Propositional imagination is sometimes also referred to as belief-like imagination.
} 
We put imagination to many different uses, from daydreaming, pretense, and engaging with fiction to decision making, counterfactual reasoning, and philosophical thought experiments. ${ }^{3}$ These varied uses fall into two broad categories: cognitive and noncognitive uses of the imagination. ${ }^{4}$ Cognitive uses of the imagination involve aiming to learn something new via the imagination. I might use my imagination to gain aesthetic knowledge, as when I use it to decide whether two flavors would compliment each other in a dish I am cooking; modal knowledge, as when I use it to decide whether round squares are metaphysically possible; or spatial knowledge, as when I use it to decide whether my luggage will fit into the overhead compartment. There is also a large literature on whether imagination is used to gain knowledge of other minds, as when I imagine what it would be like to be someone else in order to learn about their mental states (Goldman 2008). In cognitive uses of the imagination, given one's aim of learning something new, one tends to form a belief on the basis of their imagining. ${ }^{5}$ For example, I come to believe that the two flavors will not go together, or that round squares are not metaphysically possible, or

\footnotetext{
${ }^{3}$ Kind (2013) has argued that the concept of imagination is heterogenous and that no single cognitive capacity can play all the roles which are attributed to it. Thus, Kind denies that there is a single cognitive capacity underlying all of these uses. This kind of heterogeneity is compatible with the claims I will argue for in this paper. First, the epistemic structure which I sketch out is not meant to apply to all uses of the imagination but only to the use of sensory imagination in reasoning about the actual world, which is a better candidate for a single cognitive capacity. Second, I will be arguing that the imagination has a certain epistemic, rather than psychological, structure. This normative epistemic structure is compatible with the kind of psychological heterogeneity which Kind advocates. ${ }^{4}$ This distinction between cognitive and non-cognitive uses of the imagination is related to, but importantly different from, the distinction between instructive and transcendent uses of the imagination put forward by Kind and Kung (2016). According to Kind and Kung, instructive imagination enables us to "learn about the world as it is" while transcendent imagination enables us to "look beyond the world as it is" (p. 1). These two distinctions crosscut each other. One might aim to learn something from an imagining which represents a merely possible world just as one might imagine the world as it is without aiming to learn anything on its basis.

${ }^{5}$ It could also be the case that my imagining causes me to suspend judgment on whether the proposition in question is true. I'm going to set this possibility aside for simplicity's sake, but it can be accommodated by the more general characterization that cognitive uses of the imagination tend to lead to the formation of a doxastic state.
} 
that my luggage will fit into the compartment. If all goes well, this belief will constitute knowledge and one will have achieved their aim. ${ }^{6}$

In non-cognitive uses of the imagination, one does not aim to learn anything new from their imagining. When I absentmindedly daydream, I may not be aiming at anything. Or, I may be merely aiming to amuse myself. In typical daydreams, I am not aiming to learn anything. Another non-cognitive use of the imagination is when I use my imagination to put on a more convincing performance as an actor in a play. For example, I might imagine that a prop gun is a real gun in order to make my behavior more life-like and believable given the scenario represented in the play. In this case, I am using my imagination as a kind of tool to regulate my actions given my goal of putting on a convincing performance. However, I do not aim to learn anything or gain any knowledge when I use my imagination in this way. Accordingly, one does not tend to form beliefs on the basis of their non-cognitive imaginings. I do not, for example, come to believe that the prop gun is a real gun simply because I imagined it to be so.

Nearly all of these uses of the imagination, both cognitive and non-cognitive, involve constraining the content of your imaginings in certain ways. Following Kind (2016, 2018) and Kind and Kung (2016), we can distinguish between constrained and unconstrained imagination. Constrained imaginings have their content partially determined by some other mental states of the subject which act as constrainers. ${ }^{7}$ Unconstrained

\footnotetext{
${ }^{6}$ I take the aim of learning something new or gaining new knowledge to be constitutive of cognitive uses as opposed to the actual formation of new knowledge. This is because someone might imagine with the aim of learning something new, but get distracted, or fall asleep, or spontaneously combust before actually forming a belief on the basis of that imagining. I also might fail to imagine properly and end up with an unjustified belief, despite aiming to gain knowledge. Intuitively, cases like these still count as cognitive uses of the imagination.

${ }^{7}$ Plausibly, there are constraints on the imagination which do not arise as the result of other mental states but rather as a result of architectural limitations on the imagination. For example, I am unable to imagine the same surface as being both red and green not as a result of any of my mental states, but rather as a result of the functional
} 
imaginings do not have their content so determined. What is involved in the constraining relation? I do not offer a full account here. At the very least, constraining involves causation. Constrainers causally affect how the imagination unfolds. Moreover, this causal relation is sensitive to the content of the two states. Constrainers cause the imagining to have a certain content in virtue of their own content.

Both cognitive and non-cognitive uses of the imagination can be, and usually are, constrained. However, often different constrainers are at work in non-cognitive uses than in cognitive uses. Cognitive uses of the imagination often involve constraining my imaginings according to my beliefs or evidence. When I use my imagination to learn what my philosophy professor will think about the latest draft of my paper, my imagining is constrained by my beliefs about the general dispositions of my professor and the quality of my paper. On the other hand, non-cognitive imaginings have a different typical suite of constrainers. For example, my imaginative engagement with a work of fiction is constrained by my beliefs about the content of that fiction. When I use my imagination to help me to generate a wish list for my birthday, my imagining is constrained by my desires concerning what gifts I want. A given imagining can be constrained by many different mental states at the same time. ${ }^{8}$ For example, a complex imaginative episode might be constrained by my intentions, beliefs, memories, and desires. Each of these constrainers might contribute to a different part of the imagining's content. Although most imaginings

\footnotetext{
organization of the visual system. I set architectural constraints on the imagination aside in what follows and reserve the term "constrainers" for contentful mental states.

${ }^{8}$ Constraining can have both personal and subpersonal components. I might consciously choose to imagine a windmill. The fact that my imagining is so constrained is explained by a personal-level intention. But, the content of that imagining might be constrained by my beliefs and memories about windmills, along with my perceptual and imaginative capacities, in a way that is subpersonal. Even if I do not intentionally impose these constraints, and even though I may not be aware of them, they may nevertheless influence the content of my imagination.
} 
are constrained in at least some respects, examples of completely unconstrained imaginings might include daydreaming or mind-wandering.

\section{Imagination Can Justify Beliefs}

The examples of cognitive uses of the imagination given in the previous section motivate the claim that we often use our imagination to form new beliefs about what the world is like. But imagination can do more than merely causally lead to the formation of new beliefs. Imagination is also capable of justifying those beliefs. This is a point that has received a lot of attention in recent years. Many authors have argued that imagination has justificatory force not only for the more well-trodden philosophical territory of modal beliefs, but also for contingent beliefs about the actual world (Balcerak Jackson \& Balcerak Jackson 2013, Balcerak Jackson 2018, Dorsch 2016, Kind 2016, 2018, Kind and Kung 2016, Langland-Hassan 2016, Williamson 2016). ${ }^{9}$ In this section, I will briefly motivate this claim and defend it from a few popular objections.

Consider the following case:

Luggage: You are about to embark on a trip and you are choosing which piece of luggage in which to pack your belongings. You would rather not check your luggage, so you are aiming to choose a piece of luggage which you can carry on to the plane and store in the overhead compartment. You pick out a piece of luggage, but are unsure as to whether it will fit into the overhead compartment. In order to learn about whether your luggage will fit, you imagine trying to fit your luggage into the overhead compartment on an airplane at various orientations. When you imagine your luggage moving into the overhead compartment at a

\footnotetext{
${ }^{9}$ I will set the role of imagination in modal epistemology aside as it raises issues that are beyond the scope of this paper.
} 
certain orientation, you imagine it fitting comfortably inside the compartment. On the basis of this imaginative episode, you form the belief that your luggage will fit inside the overhead compartment.

Intuitively, in Luggage your belief can be justified on the basis of your imagining. Imagining that your luggage will fit into the overhead compartment makes it epistemically appropriate to believe that it will fit into the overhead compartment. Moreover, Luggage is merely one representative of a large class of cases in which imaginings play a justificatory role. Consider some of the cases discussed so far, such as when I use my imagination to form beliefs about what my professor will say about my paper, or about whether two flavors will go together in a dish I am cooking. I think that the intuitive force of these cases is sufficient to motivate the view that at least some imaginings can justify beliefs.

The thesis that imaginings can justify beliefs should not be interpreted too strongly. First, imaginative justification is fallible, in that it does not guarantee the truth of the belief. Second, it is defeasible, in that it may be subject to defeaters. Finally, it tends to be nonmaximal, in that the belief may not be justified to the greatest extent possible. For example, visually perceiving that your luggage will fit in the compartment will plausibly give you stronger justification for believing that your luggage will fit into the compartment than merely imagining it will. None of these qualifications should reduce our interest in imaginative justification. Indeed, in these respects imaginative justification is in the same boat as most other species of justification (compare: perceptual justification is also fallible, defeasible, and non-maximal).

There are two main objections to the thesis that imaginings can justify beliefs: the voluntary control objection and the heuristic objection. I want to briefly sketch responses 
to both, although I do not take anything that I will say to be conclusive. According to the voluntary control objection, imaginings cannot justify beliefs because the content of our imaginings is entirely up to us. ${ }^{10}$ For example, in Luggage I can choose to imagine my luggage as being indefinitely many sizes or shapes. Since we can imagine anything we would like, imagination cannot help us to learn about how the world actually is. Our voluntary control over the content of our imagining stops it from being world-sensitive in the way that perception, for example, is. This lack of world-sensitivity, in turn, undermines the thesis that imaginings have justificatory force.

There are two things to say in response. First, as many other philosophers have noted, constraining our imagination makes the kind of control we have over our imagination less arbitrary and therefore less likely to undermine its epistemic relevance (Kind 2016, 2018, Balcerak Jackson 2018, Langland-Hassan 2016, Williamson 2016). Indeed, if we impose the right constraints in an appropriate manner, then our imaginings can become more world-sensitive. For example, in Luggage, by constraining my imagining according to my beliefs and memories about my luggage my imagining becomes more sensitive to what my luggage is actually like, and therefore more likely to reliably lead me to a true conclusion about whether it will fit into the overhead compartment. It is true that I have voluntary control over how my imagining is constrained. However, I can choose to constrain it in ways that make it more world-sensitive and thus more reliable. Second, to preview my arguments in the next section, not just any imaginings justify beliefs. Only imaginings which meet certain conditions have justificatory force. In the next section, I

\footnotetext{
${ }^{10}$ This has been argued for by Wittgenstein (1948/1980) and O'Shaughnessy (2000). For discussion see Kind (2016, 2018) and Balcerak Jackson (2018).
} 
will argue for one necessary condition on imaginative justification that I think is particularly plausible, having to do with which mental states are used as constrainers on the imagining. Importantly, whether our imaginings meet this further condition is not entirely up to us. Thus, although we can imagine anything we would like, we cannot just imbue any imagining we like with justificatory force.

The heuristic objection concedes that we often form beliefs after imagining something. It also concedes that those beliefs can be justified. However, it maintains that imagination is a mere heuristic for generating ideas which are justified by other general cognitive capacities such as reasoning, perception, and memory. Although imagination may be a useful heuristic, it does not itself have justificatory force. What explains our intuition that the belief formed on the basis of the imagination is justified in Luggage is that your prior beliefs and memories about the luggage which constrain the imagining are themselves sufficient for the justification of the resulting belief. More generally, when one forms a justified belief on the basis of an imagining, that belief is justified by the constrainers of that imagining and not the imagining itself. ${ }^{11}$

I concede that there are probably cases in which imagination plays a heuristic rather than a justificatory role. ${ }^{12}$ For my purposes, I simply need to show that there are some cases where imagination plays a justificatory role over and above a subject's other mental states. I also concede that there may be cases in which a subject's constraining beliefs, memories, and perceptions could justify the resulting belief if the resulting belief were based on those mental states. The question is whether beliefs which are based on imaginings are thereby

\footnotetext{
${ }^{11}$ This objection is most forcefully argued for by Shannon Spaulding (2016). A similar point is made by Sartre (1948).

${ }^{12}$ One example from the empirical literature is the availability heuristic, where how easy a certain scenario is to imagine is used as a heuristic for how likely that scenario is to obtain.
} 
justified in virtue of being based on that imagining. Sometimes imagination may be one of many ways to arrive at a justified belief. This does not undermine the thesis that imaginings have justificatory force.

Nevertheless, it is plausible that there are many imaginings which are in a position to justify beliefs that the constraining states are not in a position to justify on their own. An analogy to reasoning is helpful here. Consider a case of deductive reasoning where one starts with a set of axioms and traces out their logical entailments to arrive at a complicated mathematical theorem. Even if the initial set of axioms really does logically entail the resulting belief in the mathematical theorem, it is not enough to simply form the resulting belief on their basis. If the proof is sufficiently complicated, one cannot move in a single step from the axioms to the conclusion in an epistemically appropriate manner. One must also go through a number of inferential steps tracing out a proof for the conclusion from the axioms in order for the resulting belief to be justified. Going through these inferential steps allows the subject to transition from axioms to theorem in an epistemically appropriate manner.

I contend that a similar process is at work in imagination. Epistemic uses of the imagination often involve tracing out the entailments of the constrainers in order to arrive at a new belief. For example, in Luggage, you begin with a set of beliefs and memories about the size and shape of the luggage and the overhead compartment. You then go on to develop that information by imagining the luggage undergoing various spatial manipulations relative to the compartment until you imagine it fitting comfortably inside, all the while monitoring your imagination to make sure it remains appropriately constrained. While deductive reasoning is good for tracing out the logical entailments of a 
set of beliefs, imagination is quite good for tracing out other kinds of entailments, such as spatial, causal, or nomological entailments.

As in the case of deducing a complicated mathematical theorem, the process of imagining can make certain inferential steps epistemically appropriate that otherwise would not be. In the case of Luggage, directly inferring the proposition that the luggage will fit into the overhead compartment from your prior beliefs and memories may be too great a leap. For example, it itself might involve some complex mathematical reasoning about the geometry of the two objects. On the other hand, imagination is well-suited for tracing out those entailments. By translating the content of your beliefs and memories into an imagining, one can easily check whether the luggage will fit by operating on that content and imagining the luggage undergoing various spatial manipulations relative to the compartment until you imagine it fitting comfortably inside. This process is clearly epistemically relevant. It makes apparent to the subject what was only implicit in the constrainers: that the luggage will fit. Without going through the process of tracing out what follows from the constrainers in imagination, the resulting belief would not be justified. If this is right, it undermines the idea that imagination is a mere heuristic. Imagination adds something epistemically over and above the constrainers. It allows subjects to transition from their initial set of evidence to a new belief in an epistemically appropriate manner.

\section{The Justificatory Force Condition}

So far, I have argued that imaginings can justify beliefs. In this section, I will argue for the following necessary condition on imaginative justification: 
The Justificatory Force Condition: The justificatory force of an imagining is determined, at least in part, by the justificatory force of its constrainers.

This condition is interesting in its own right, but it will also figure prominently in my argument that imaginings can have an epistemic status. I will argue for it by considering a series of cases and showing how it best explains their epistemic features.

Although Luggage is a plausible case of imaginative justification, the case is actually under described. Consider the following variant on Luggage:

Unconstrained Luggage: You are daydreaming about a vacation you are going to take soon and just happen to imagine a piece of luggage fitting into the overhead compartment of a plane. You imagine the luggage as your luggage, but because you are merely daydreaming you do not bring any of your beliefs about the size or shape of your luggage nor of the size or shape of a typical overhead compartment to bear on the content of this imagining. You form the belief that your luggage will fit into the overhead compartment on the basis of this imagining.

Intuitively, this belief is not justified. Given that your imagining is completely unconstrained, you cannot learn anything about what the world is like on the basis of this imagining. As noted above, many philosophers have made this observation about the importance of constraints to the epistemology of the imagination. For example, Kind argues that our ability to "constrain our imaginings in light of facts about the world [is what] enables us to learn from them" (Kind 2016 p. 146). Given that daydreams and fantasies cannot justify beliefs, it is plausible that only constrained imaginings have justificatory force. 
Obviously, not just any constraints will do. Consider the following variant of Luggage:

Desire-based Constrained Luggage: You really want your luggage to fit into the overhead compartment, because it would be a major inconvenience if it did not fit. Your desire for your luggage to fit acts as a constrainer on your imagination. This desire causes you to imagine your luggage as fitting into the overhead compartment. You go on to form the belief that your luggage will fit into the overhead compartment on the basis of this imagining.

This case is, essentially, an imaginative analog of wishful thinking. Your imagining is constrained because you are not just letting it wander aimlessly. Its content is at least partially determined by the content of your desires. Thus, in this case your desires act as constrainers on your imagining. It is a truism that desires do not epistemically justify beliefs. Similarly, as Desire-based Constrained Luggage makes intuitively clear, imaginings which are constrained by your desires do not justify beliefs.

So, for an imagining to have justificatory force it cannot simply be constrained in any old way. A natural thought at this point is to impose some limits on how an imagining must be constrained in order to have justificatory force. Desire-based Constrained Luggage suggests one plausible limitation. Perhaps, in order to have the power to justify beliefs, imaginings must be constrained by mental states with assertoric force: mental states which assert their contents as true. Desires do not have assertoric force. Desiring that your luggage will fit does not assert its content as true; it does not make it seem to the subject that their luggage actually will fit. Indeed, we quite often desire contents that we know to be false. On the other hand, mental states such as beliefs, perceptions, and memories all 
have assertoric force. They all assert their contents as true. Believing, perceiving, or remembering that $p$ all seem to bear on how the world actually is, unlike desiring that $p$. The condition that an imagining must be constrained by mental states with assertoric force in order to justify beliefs enjoys some intuitive pull. After all, only imagining what the world is actually like (as opposed to what you want it to be like) promises to help us learn anything about what the world is actually like!

To see why even the assertoric force condition is not enough, consider the following case:

Unjustified Constrained Luggage: You are aiming to learn whether your luggage will fit in the overhead compartment and, order to realize this aim, you constrain your imagining with your beliefs and memories about their shapes and sizes. However, your beliefs about their sizes are unjustified, and your memories are extremely hazy and imprecise. You go on to form the belief that your luggage will fit on the basis of your imagining.

Intuitively, this belief is unjustified because it is based on an imagining which is constrained by mental states which themselves lack justificatory force. In other words, the belief is unjustified because the imagining is constrained by poor evidence. The imagining inherits the justificatory force of its constrainers. This suggests the following necessary condition on imaginative justification:

The Justificatory Force Condition: The justificatory force of an imagining is determined, at least in part, by the justificatory force of its constrainers. ${ }^{13}$

\footnotetext{
${ }^{13}$ Although being constrained by states with justificatory force is necessary for imaginative justification, it is not sufficient. Intuitively, one can start with good constrainers but still imagine poorly, or unreliably, or imprecisely, or irresponsibly in ways that undermine the justificatory force of the imagining.
} 
This condition has gone largely unnoticed. For example, Kind's emphasis on "constrain[ing] our imaginings in light of facts about the world" (2016 p. 146) obscures the fact that we do not have unfettered access to those facts about the world. We cannot directly constrain our imaginings according to what the world is like. The best we can do is constrain our imaginings according to how we represent the world to be. And the epistemic status of those constrainers - whether our representations of the world are supported by our evidence or notmediates the ability of the imagination to justify beliefs.

Finally, consider the following variant of Luggage:

Justified Constrained Luggage: You are aiming to learn whether your luggage will fit in the overhead compartment and, in order to realize this aim, you constrain your imagining with your beliefs and memories about their shapes and sizes. These beliefs are justified, and your memories are vivid and precise. Perhaps you are even currently looking at your luggage and have excellent perceptual evidence of its size and shape. You go on to form the belief that your luggage will fit into the overhead compartment on the basis of this imagining.

Intuitively, this belief is justified. The justificatory force condition explains the difference between this case and the previous one. In Justified Constrained Luggage, the constrainers have justificatory force while in Unjustified Constrained Luggage they do not. The justificatory force condition also explains the other cases we considered in this section. Unconstrained Luggage does not have justificatory force because there are no constrainers in the first place, and Desire-based Constrained Luggage does not have justificatory force because desires do not have epistemic justificatory force. Thus, there is good evidence for the justificatory force condition. It offers a unified explanation of the epistemic features of 
each of the cases considered in this section. The justificatory force of the constrainers modulates the justificatory force of the imagining they constrain.

\section{Imaginings are Justified Justifiers}

Now we are faced with a further question. What explains why imaginings have the power to justify beliefs? This question has gone largely unexplored. According to the proposal I favor, imaginings justify beliefs in virtue of themselves being epistemically justified. When a subject properly bases a belief on such an imagining, that positive epistemic status is transferred to the belief. Conversely, imaginings which manifest a negative epistemic status or no epistemic status at all will fail to have justificatory force. In this section, I will argue for this view by showing how it explains some rather puzzling features of imaginative justification entailed by the justificatory force condition.

First, it will be useful to show why a rather flat-footed view about the grounds of imaginative justification does not work. The question of what explains why the imagination is capable of justifying beliefs is particularly puzzling because, for one thing, not all imaginings have justificatory force. Imagining any arbitrary content does not thereby justify a belief with that content. Certain other conditions must be met. This platitude rules out a whole class of potential views which locate the grounds of imagination's justificatory force in some intrinsic feature of the imagination. For example, one might think that the justificatory force of the imagination is grounded in the attitude one takes towards a content in imagining it, or in the phenomenology of imagination. If either of these proposals were true, then all imaginings would have justificatory force. But this is not so; many imaginings do not have justificatory force. In this respect, imaginative justification is very unlike perceptual justification. Perception justifies 
belief categorically, plausibly in virtue of its phenomenology. Even in cases of illusion and hallucination, perception still possesses justificatory force in virtue of the kind of state that it is.

There is another important difference between imaginative justification and perceptual justification: while perceptual justification is immediate, imaginative justification is often mediate. Mediate justification is justification which depends in part on the justificatory status of a subject's other beliefs. The justificatory force condition entails that when an imagining is constrained by one or more beliefs, those beliefs must be justified in order for the imagining to have justificatory force. This is because beliefs are justified justifiers: they only have justificatory force when they are themselves justified. This is not to say that imaginative justification is always mediate. There may be imaginings with justificatory force which are not constrained by beliefs. It is enough for my purposes that imaginative justification is sometimes mediate. However, given how plausible it is that beliefs are an important class of constrainers for cognitive uses of the imagination, then it is also quite plausible that imaginative justification will overwhelmingly often be mediate.

Nevertheless, imaginative justification is unlike paradigmatic cases of mediate justification, such as inference with beliefs, in certain crucial respects. For example, when one forms a justified belief that $q$ by inferring it from their prior justified beliefs that $p$ and that if $p$ then $q$, it seems like the justification of the resulting belief is mediate precisely because that belief is based on other beliefs. It is in virtue of the basing relation that the justificatory statuses of the prior beliefs determine the justificatory status of the resulting belief. If the resulting belief was not based on the prior beliefs, but instead on a perceptual experience, then the justification the resulting belief enjoys would no longer be mediate. Indeed, many philosophers use the locution of justification being "transferred" or 
"transmitted" from belief to belief via the basing relation. In the case of inference, new justification is not generated. Instead, existing justification is transmitted from the prior beliefs to the new belief formed on their basis.

In the case of imaginative justification, the resulting belief is based upon the imagining and not upon the constraining beliefs. Thus, it is mysterious why the justificatory status of the constraining beliefs determines the justificatory status of the resulting belief. Assuming that imaginings cannot themselves have an epistemic status, the transfer of justification would have to skip a step in the process that leads to the resulting belief. However, the step that is skipped (i.e. the imagining) is precisely the step upon which the resulting belief is based. Not only would this undermine the epistemic relevance of the imagination, which we have already seen good reasons for accepting, but this is radically unlike other cases of mediate justification and threatens to undermine the widely accepted epistemic significance of the basing relation. The epistemic status of the resulting belief should not be sensitive to the epistemic status of states that it is not based on. ${ }^{14}$ So, it seems that we must posit a brute justificatory dependence relation between the constrainers and the resulting belief which itself goes unexplained in order to explain the transfer of justification. This is obviously an unsatisfying explanation of the epistemic facts. Positing a brute justificatory dependence relation does little more than restate the phenomenon to be explained.

However, the transfer of justification from the constrainers to the belief formed on the basis of the imagining is not at all mysterious if imaginings can have epistemic status. ${ }^{15}$

\footnotetext{
${ }^{14}$ The fact that the constraining beliefs causally influence the imagining does not assuage this worry. Mere causation is, in general, not sufficient for the transfer of justificatory status.

${ }^{15}$ This does not entail that all imaginings have epistemic status. Intuitively many do not, such as imaginings that are the result of engaging with fiction or daydreaming. One plausible account of this difference might appeal to the
} 
This suggests a picture of imaginative justification according to which the epistemic status of the beliefs which constrain an imagining are transferred to the imagining itself, and then on to beliefs which are based on that imagining. In the next section, I will argue that imaginings can be epistemically based on their constrainers. This argument will further motivate this picture of the epistemic role of the imagination because it explains how imaginings come to have epistemic status in the first place. For now, notice that the thesis that imaginings can have epistemic status offers a satisfying explanation of the mediacy of imaginative justification. It explains why and how the justificatory status of the resulting belief depends on the justificatory status of the beliefs which constrain the imagination without being based on them. Indeed, it also explains the justificatory force condition more generally. Imaginings inherit the justificatory force of their constrainers because the imaginings are either justified or unjustified on the basis of those constrainers. ${ }^{16}$ This thesis also explains the intuitively plausible idea that the strength (or degree) of imaginative justification at least partially depends on the justificatory strength of the constrainers. Finally, and most obviously, the thesis that imaginings can have epistemic status explains why imaginings do not have categorical justificatory force in the way that it is commonly

different aims or goals with which one imagines. On this view, the aim with which you imagine sets the standards which the imagining can be held to. When one aims to imagine veridically, the resulting imagining is evaluable according to how well it is supported by one's evidence. When one does not aim to imagine veridically, it would be inappropriate to hold it to the standard fixed by one's evidence. Although I am sympathetic to this account, I will not pursue it further here.

${ }^{16}$ The fact that imaginings are often constrained by many different mental states raises many interesting questions about their epistemic structure. For example, assuming that imaginings have epistemic status, are imaginings justified simpliciter, or justified relative to certain parts of their content? Suppose you constrain your imagining in Luggage with a justified belief about the size of your luggage but an unjustified belief about its color. Intuitively, your belief that your luggage will fit in the compartment is still justified by your imagining, despite your imagining being partially constrained by an unjustified belief. This lends intuitive support to the thesis that imaginings have epistemic status only relative to certain contents. In this example, your imagining is justified with respect to the size content and unjustified with respect to the color content. This, in turn, has ramifications for which beliefs it is in a position to justify. If this is right, then it marks an important disanalogy between the epistemic structure of imaginings and beliefs. Beliefs are plausibly justified or unjustified simpliciter. 
thought that perception does. Imaginative justification depends on the epistemic status of the imagining in question. When imaginings are epistemically unjustified, beliefs based on them will also be unjustified. Instead of attributing in an ad hoc manner a kind of epistemic structure to imagination which is unlike other paradigmatic cases of mediate justification, the view on offer here assimilates imaginative justification to other cases of justification through reasoning where justification is transmitted from the mental states used in the reasoning process to the belief formed on their basis. ${ }^{17}$

This account of imaginative justification offers a satisfying explanation of Luggage. In this case, your belief that the luggage will fit into the compartment is justified to the extent that you properly base that belief on an imagining which is justified and your imagining is justified to the extent that you properly constrain it with justified beliefs about the size and shape of the luggage and the compartment. Furthermore, this account plausibly generalizes to many other cases of imaginative justification. For example, one's belief that two flavors will go well together in a dish is justified on the basis of one's imagining just in case one properly constrains their imagining with vivid memories and justified beliefs about what those two flavors taste like. Many of the other cognitive uses of the imagination discussed above seem to have an analogous structure. Nevertheless, further work is needed to see just how far this structure generalizes. ${ }^{18}$

Here is another way of reconstructing the dialectic. The question is whether imaginings are unjustified justifiers or justified justifiers. Perception is the prototypical

\footnotetext{
${ }^{17}$ See Myers (forthcoming) for an independent argument that cognitive uses of the imagination are best understood as a form of reasoning.

${ }^{18}$ Although there is good reason to think that this account generalizes to many cases of imaginative justification, I do not claim that it generalizes to all cases. For example, I suspect that the role of imagination in justifying modal beliefs is importantly different to the role of imagination in Luggage. There may be other cases in which imaginings justify beliefs in conjunction with an explicit inference about the imagining's reliability, and thus do not require the imagining itself to be justified.
} 
unjustified justifier. However, perception and imagination differ in their epistemic structure. Perception has categorical justificatory force while imagination does not, in virtue of its being subject to the justificatory force condition. Furthermore, the categorical justificatory force of perception is closely linked to its status as an unjustified justifier. Thus, imaginings do not exhibit the right kind of epistemic structure to be unjustified justifiers. But, if they aren't unjustified justifiers then they must be justified justifiers. As it so happens, this meshes well with our antecedent understanding of the epistemic structure of justified justifiers, such as beliefs. Imaginative justification has much in common with justification by inference, notably the transfer of justificatory force from the inferential inputs (or constrainers) to the output of the inference. In the case of inference, this is explained by the epistemic status of those inputs being transferred along each inferential transition such that each step is a justified justifier. I have suggested that we should avail ourselves of an analogous explanation in the case of imagination. The epistemic status of the constrainers is transferred to the imagining and finally to the beliefs which are based on that imagining. Thus, the epistemic structure of imaginative justification is best explained by the thesis that imaginings are justified justifiers. ${ }^{19}$

\section{Imaginings Can Be Based on Evidence}

In the previous section, I argued that imaginings can manifest an epistemic status. In this section, I will explore how imaginings come to have an epistemic status in the first place. In short, my answer is that imaginings come to have an epistemic status by being based on evidence. More precisely, I will argue that the constraining relation involves a

\footnotetext{
${ }^{19}$ Both the thesis that imaginings can have epistemic status and the argument I presented in support of this thesis bear obvious similarities to Susanna Siegel's view that perceptual experiences can have epistemic status (Siegel 2017). Nevertheless, it is worth keeping in mind the various dissimilarities between perception and imagination when comparing the two views.
} 
kind of basing such that imaginings can be based on their constrainers. This functions both as an independent argument for imaginings having epistemic status, and as a way of fleshing out my account of the structure of imaginative justification.

Paradigmatically, the epistemic basing relation holds between beliefs and evidence. I do not take a stand on the nature of evidence here. For my purposes, the uncontroversial view that beliefs, memories, and perceptual states can sometimes count as evidence is sufficient. Beliefs accrue their epistemic status in virtue of the evidence they are based on. In some cases, a subject may possess both good evidence and bad evidence for a belief, and which piece of evidence the belief is based on determines its epistemic status.

The view that imaginings can be based on evidence strongly motivates the view that imaginings can have an epistemic status. After all, if imaginings can stand in the very same relation to a subject's evidence that their beliefs do, and beliefs accrue their epistemic status in virtue of standing in that relation, then there is prima facie reason to think that imaginings can accrue epistemic status as well.

There is a dialectical problem with arguing that imaginings can be based on evidence. The problem is that the nature of the epistemic basing relation is a point of widespread disagreement within epistemology. Instead of arguing for a set of necessary and sufficient conditions for basing and then showing how the relationship between imagination and evidence meets those conditions, I will instead proceed by way of identifying some relatively uncontroversial markers of the basing relation, and then argue that the relation between imagination and a subject's prior beliefs exhibits those markers. This will allow me to remain relatively neutral on the correct theory of basing while still making progress on the issue of the epistemic status of the imagination. Thus, I intend for my argument to 
have dialectical force regardless of the account of basing that one accepts. I do not think that any of the markers I identify are sufficient for basing on their own, and there is much debate over whether they are individually necessary. Nevertheless, the markers, taken together, are strong evidence for basing. An instance of the basing relation which exhibits all of these markers is a central case of basing, regardless of whether basing can also occur in the absence of some of these markers.

First, and perhaps most uncontroversially, when one bases a belief on evidence, that belief must have been at least partially caused by that evidence (Moser 1989, McCain 2012). For example, suppose I perceive a water bottle and I form the belief that there is a water bottle in front of me. However, I formed this belief because of wishful thinking. I am thirsty and I really want a bottle of water. My perceptual state does not enter into the causal story of why I formed that belief. It is clear that I did not base my belief on my perceptual state. My perceptual state is evidence for that belief, but it is not the evidence upon which my belief was based. Second, when one bases a belief on some evidence, the content of the belief must be sensitive to the content of the evidence (Kornblith 2012, Sylvan and Lord forthcoming). That is, when one bases a belief on some evidence, one forms a belief with a certain content because of or in virtue of possessing some evidence with a certain content. ${ }^{20}$

It is relatively straightforward that imaginings meet both the causal and contentsensitivity conditions on basing. Constrained imaginings were defined as imaginings which

\footnotetext{
${ }^{20}$ It is very difficult to say exactly what this sensitivity amounts to. If one stipulates that the belief must be sensitive to or caused by the fact that the evidence epistemically supports its content, then it will be impossible to base beliefs on bad evidence. On the other hand, merely being causally sensitive to the content is not sufficient because mere associations between mental states are content-sensitive without involving basing (Boghossian 2014). I will remain neutral on the different ways of spelling this condition out, since not much hangs on these more subtle distinctions.
} 
have their content partially determined by some other mental states of the subject. Exactly how this is achieved is obviously an empirical question. However, any plausible cognitive architecture of this process will involve the constrainers exerting a causal influence on the imagining.

Furthermore, this causal process proceeds in a way that is sensitive to the content of the constrainers. For example, when I imagine what my office looks like, this imagining is constrained by my beliefs about my office. For one thing, I believe that the walls of my office are white. In virtue of my belief having this content, I imagine the walls of my office as being white. Were I to believe that the walls of my office were a different color, I would imagine them as being that different color, given my goal of imagining what my office actually looks like.

There is a much stronger mark of the basing relation that imagination also possesses. This is the mark of believing or taking one's evidence to support or to give a reason for forming a state with a certain content (Boghossian 2014, Leite 2008). We can and often do explicitly take certain constraining states to be good reasons for our imaginings. I think this is clear from thinking about Luggage. Suppose I am consciously deliberating about whether my luggage will fit into the compartment. When I set up the scenario in my imagination, I might explicitly take my beliefs about the size of the luggage to give me reason to imagine the luggage as being that size. I'm aware that my beliefs give me reasons to form an imaginative state with a certain content, given my goal of learning whether my luggage will actually fit into the compartment. I might even form the occurrent belief that my belief that the luggage is a certain size gives me reason to imagine it as that size. If, in the process of this deliberation, I were to notice that the imagined size of the luggage does not match 
the size that I believe the luggage to be, I would explicitly take that belief as a reason to alter the content of my imagination. Thus, we often take our evidence to give us reason to imagine certain contents and constrain our imaginings accordingly. I am not claiming that basing must be part of explicit, personal-level deliberation. But, explicit deliberation about what to believe is certainly a paradigm example of basing, and in some ways, it is less controversial than putative examples of sub-personal or relatively automatic basing. Since imaginings can satisfy this more demanding conception of basing, this is even stronger evidence that imaginings can be based on evidence.

There is one final, closely related, mark of the epistemic basing relation that imagination exhibits. Basing involves a kind of epistemic responsibility. Typically, when one bases a belief on a piece of evidence, one can be held epistemically responsible for basing the belief on that evidence (Boghossian 2014, Neta 2019). This is a species of epistemic evaluation over and above evaluating whether the evidence in question stands in an epistemic support relation to the belief. For example, I might base a belief in a complex mathematical proposition on some other mathematical belief. Unbeknownst to me, there might actually be some complex proof from the content of my prior belief to the proposition in question. Thus, my belief is good evidence: it actually supports the proposition. However, if I have no reason to believe that there is such a proof, and I do not recognize the entailment relation from the my prior belief to the proposition in question, then I was epistemically irresponsible in basing my belief on that reason, even though it is good evidence for that belief.

Evaluating whether someone is epistemically responsible in forming a belief is also a different kind of epistemic evaluation from evaluating whether the belief itself is justified. 
On many theories of epistemic justification, epistemic responsibility is a necessary or sufficient condition on the belief being justified. But the two kinds of normative evaluation are at least conceptually separable. One is an evaluation of the agent who forms the mental state and one is an evaluation of the mental state itself. That being said, if one can be held epistemically responsible for a certain mental state, then that state is a good candidate for having an epistemic status. This is plausible in the case of belief. One can be held epistemically responsible for forming a belief in a certain way because the belief is itself epistemically evaluable. It seems incoherent to hold someone epistemically responsible for forming a mental state which is not itself epistemically evaluable. For example, if you suppose that the earth is flat in the course of some train of suppositional reasoning, it would be infelicitous for me to criticize you for being epistemically irresponsible for that supposition. If suppositions are not answerable to one's evidence or other epistemic factors, how could I hold you epistemically responsible? You might be responsible along other dimensions of normative appraisal, but not along the epistemic dimension.

I think an intuitive case can be made for the thesis that subjects can be held epistemically responsible for their imaginings. Consider the following variation on Luggage (adapted from a similar case in Balcerak Jackson \& Balcerak Jackson 2013). Suppose that someone is using their imagination to figure out whether their luggage will fit in the overhead compartment on the airplane. However, their desire to not have to pay any extra fees to check their luggage along with their excessive and irrational optimism about how large the overhead compartment is cause them to imagine their luggage fitting inside the compartment. It seems to me that, even if you are skeptical about the epistemic status of imaginative states themselves, it would be quite natural to hold this agent 
epistemically responsible for their imagining. You might rightly criticize them for letting irrational factors influence the content of their imagination. It is intuitive to say that they ought to have constrained their imagination in light of their evidence about the size of the overhead compartment and ought not to have constrained it in light of their irrational optimism. These criticisms are natural to make even if their imagination was veridical and their luggage really does fit in the compartment.

The best explanation of the fact that agents can be held epistemically responsible for their imaginings is that imaginings can be based on evidence. ${ }^{21}$ In the above example, it is plausible the subject was epistemically irresponsible in imagining the luggage fitting in the compartment because it was partially based on their excessive optimism and wishful thinking and not solely based on their evidence about the sizes of the luggage and the compartment. Basing implies epistemic responsibility, but mere causation does not.

In this section, I have argued that the constraining relation possesses four prima facie markers of the epistemic basing relation: causation, content-sensitivity, explicit taking, and epistemic responsibility. It is quite plausible that, taken together, these four markers are strong evidence for the presence of basing. At the very least, denying that these four properties are evidence for basing would commit one to an idiosyncratic view of basing. ${ }^{22}$

The thesis that imaginings can be based on evidence is interesting in its own right. However, it also ties together a few of the other key points I have argued for in this paper.

\footnotetext{
${ }^{21}$ The mere fact that imaginings bear a causal relationship to their constrainers is not enough to explain why one can be held epistemically responsible for how they constrain their imagination. Causation is not sufficient for epistemic responsibility. After all, we do not hold subjects responsible for automatic, involuntary, and sub-personal causal relationships between their mental states. The fact that one can be held epistemically responsible for how they constrain their imagination is evidence that imaginings can stand in an epistemically thicker relation than mere causation to their constrainers.

${ }^{22}$ Even if one does not think that these markers are evidence for basing, they nevertheless are evidence that the constraining relation has epistemic/normative features and thus is a good candidate for being the kind of relation that epistemic justification can be transferred along.
} 
For example, the thesis that imaginings have justificatory force when they are based on good evidence both explains and subsumes the justificatory force condition. It explains the justificatory force condition because it is commonly accepted that basing is the "mechanism" by which justification is transferred from state to state. It subsumes the justificatory force condition because good evidence has justificatory force. Furthermore, the thesis that imaginings can be based on evidence also independently motivates the thesis, argued for in the previous section, that imaginings can be epistemically justified or unjustified. Since beliefs accrue their epistemic status in virtue of the evidence they are based on, it is plausible to think that imaginings would accrue epistemic status in the same way.

The arguments of the previous two sections suggest a fundamental epistemic similarity between imaginings and beliefs. Both are justified justifiers. They both epistemically mediate between the evidence one already possesses and the beliefs one goes on to form on their basis. This is an interesting and surprising similarity, especially given the prima facie differences between beliefs and imaginings. Nevertheless, this similarity should not be overstated. Although imaginings and beliefs play the same epistemic role, they play this role in different ways. For example, it is plausible that beliefs play this role by entering into inferential transitions facilitated by their discursive structure, and sensory imaginings play this role by entering into non-inferential transitions facilitated by their imagistic structure. An exploration of the epistemic differences between imaginings and beliefs will need to wait for another time.

\section{Conclusion}


Imaginings manifest an epistemic status: they are epistemically evaluable as justified or unjustified. This epistemic status grounds their ability to justify beliefs, and they accrue this status in virtue of being based on evidence. I argued for this view by showing that it offers a satisfying explanation of why the justificatory force of the imagination systematically depends on how it is constrained, and in particular on the epistemic quality of its constrainers. This picture of imaginative justification raises questions about the scope of epistemic normativity and the nature of the imagination which I have not had space to address. Nevertheless, the view that imaginings are justified justifiers allows us to explain how imaginings justify beliefs, and thereby give a plausible and satisfying account of what many philosophers have taken to be an especially puzzling feature of imaginings, in terms of their playing an epistemic role that is already quite familiar in epistemology. Understanding the imagination as the kind of thing which can manifest an epistemic status offers a promising way forward for theorizing about the epistemology of the imagination. 


\section{List of Works Cited}

Balcerak Jackson, Magdalena, \& Balcerak Jackson, Brendan (2013). Reasoning as a source of justification. Philosophical Studies, 164(1), 113-126.

Balcerak Jackson, Magdalena (2018). Justification by imagination. In Fiona Macpherson \& Fabian Dorsch (eds.), Perceptual Imagination and Perceptual Memory. Oxford University Press. pp. 209-226.

Boghossian, Paul (2014). What is inference? Philosophical Studies 169 (1):1-18.

Dorsch, Fabian (2016). Knowledge by imagination - how imaginative experience can ground knowledge. Teorema: International Journal of Philosophy 35 (3): 87-116.

Goldman, Alvin L. (2008). Simulating Minds: The Philosophy, Psychology, and Neuroscience of Mindreading. Oxford University Press.

Kind, Amy (2013). The heterogeneity of imagination. Erkenntnis 78 (1):141-159.

Kind, Amy (2016). Imagining under constraints, in Amy Kind and Peter Kung (eds.), Knowledge Through Imagination. Oxford University Press, 145-59.

Kind, Amy (2018) How imagination gives rise to knowledge. In F. Dorsch \& F. Macpherson (eds.), Perceptual memory and perceptual imagination. New York: Oxford University Press.

Kind, Amy \& Kung, Peter (2016) Introduction: the puzzle of imaginative use. In Amy Kind and Peter Kung (eds.), Knowledge Through Imagination. Oxford University Press, pp. 1 37.

Kornblith, Hilary (2012). On Reflection. Oxford University Press.

Langland-Hassan, Peter (2016). On Choosing What to Imagine. In A. Kind \& P. Kung (eds.), Knowledge Through Imagination. Oxford University Press. pp. 61-84.

Leite, Adam (2008). Believing one's reasons are good. Synthese, 161(3): 419-441.

McCain, Kevin (2012). The interventionist account of causation and the basing relation. Philosophical Studies, 159: 357-382.

Moser, Paul (1989). Knowledge and Evidence, Cambridge: Cambridge University Press.

Myers, Joshua (forthcoming). Reasoning with Imagination In A. Kind \& C. Badura (eds.), Epistemic Uses of the Imagination. Routledge. 
Neta, Ram (2019). The basing relation. Philosophical Review 128 (2):179-217.

O'Shaughnessy, Brian (2000). Consciousness and the World. Oxford: Clarendon Press.

Sartre, Jean-Paul (1948). The Psychology of Imagination. New York: Philosophical Library.

Siegel, Susanna (2017). The Rationality of Perception. Oxford University Press.

Spaulding, Shannon (2016). Imagination Through Knowledge. In Amy Kind \& Peter Kung (eds.), Knowledge Through Imagination. Oxford University Press. pp. 207-226.

Sylvan, Kurt \& Lord, Errol (forthcoming). Prime Time (for the Basing Relation). In J. Adam Carter \& Patrick Bondy (eds.), Well-Founded Belief: New Essays on the Basing Relation.

Williamson, Timothy (2016). Knowing by Imagining. in Amy Kind and Peter Kung (eds.), Knowledge Through Imagination. Oxford University Press. pp. 113-123.

Wittgenstein, Ludwig (1948/1980). Remarks on the Philosophy of Psychology, Vol. II, ed. G. H. Von Wright and Heikki Nyman. Chicago: University of Chicago Press. 